Methods Following a quantified hypoxic-ischaemic insult, 16 male piglets were randomized to either hypothermia alone $33.5 \circ \mathrm{C}$ from 4-22h, $\mathrm{n}=7$ ) or DXM plus hypothermia ( $\mathrm{n}=9$ ). Mean arterial blood pressure $(\mathrm{MABP})$ was measured continuously; when MABP was < $40 \mathrm{mmHg}$, a saline bolus was given followed by inotropes. At $48 \mathrm{~h}$ the experiment was terminated.

Results There was no difference in baseline variables. Compared to hypothermia only, the DXM hypothermia group required more saline, adrenaline and cardiac arrests (all $p<0.05)$. These adverse events occurred at both high and low dose DXM.

Abstract 55 Table 1 Volume replacement, adrenaline and cardiac arrests

\begin{tabular}{lll}
\hline & Hypothermia alone $(\mathbf{n}=\mathbf{7})$ & Hypothermia plus $\mathbf{D X M}(\mathbf{n}=\mathbf{9})$ \\
\hline Saline replacement $(\mathrm{ml} / \mathrm{kg})$ & $0.45 \pm 0.18$ & $0.88 \pm 0.29^{*}$ \\
Adrenaline for resuscitation $(\mu)$ & $28.57 \pm 23.82$ & $211.11 \pm 69.29^{*}$ \\
Cardiac arrest & 2 out of 7 & 7 out of $9 \wedge$ \\
Fatal cardiac arrest & 1 out of 7 & 4 out of 9 \\
${ }^{*} p<0.05$ unpaired $t$ test ${ }^{\wedge} p<0.05$, Chi squared test & \\
\hline
\end{tabular}

Conclusion Adverse cardiovascular events with low and high dose DXM combined with cooling occurred mainly after $16 \mathrm{~h}$ and could be due to perturbed central autonomic function, vasoconstriction via peripheral alpha adrenoceptor stimulation or effects on the imidazoline receptor.

\section{SAFETY OF HIGH-DOSE ERYTHOPOIETIN FOR NEUROPROTECTION IN PRETERM INFANTS}

doi:10.1136/archdischild-2012-302724.0056

${ }^{1} \mathrm{JC}$ Fauchere, 'BM Koller, ${ }^{2} \mathrm{~A}$ Tschopp, 'HU Bucher, Swiss EPO Neuroprotection Trial Group. 'Division of Neonatology, Univ. Hospital Zurich; ${ }^{2}$ Biostatistics, Institute of Social and Preventive Medicine, Univ. Zurich, Zurich, Switzerland

Background Erythropoietin has been shown to be protective against hypoxic-ischaemic and inflammatory injuries in cell culture, animal models of brain injury, and in clinical trials in human adults. A multicentre randomized placebo-controlled trial was started to investigate whether early administration of high dose recombinant human erythropoietin (rhEpo) in very preterm infants improves neuro-developmental outcome at 24 months.

Aim Interim analysis of neonatal complications until discharge from hospital.

Results 395 preterm infants were recruited in 5 centres. 206 infants had received $\left(n_{t}\right) 3,000 \mathrm{U} / \mathrm{kg}$ body weight rhEpo, and 189 infants $\mathrm{NaCl} 0.9 \%$ intravenously at 3, 12-18 and 36-42 hours after birth.

\section{Abstract 56 Table 1}

\begin{tabular}{llll}
\hline & EPO (n=206) & Placebo (n=189) & $\mathbf{p}$ \\
\hline GA (wks); mean (SD) & $29.3(1.6)$ & $29.3(1.6)$ & 0.99 \\
BW (g); mean (SD) & $1232(373)$ & $1231(314)$ & 0.99 \\
Death n (\%) & $12(5.9)$ & $11(5.9)$ & 0.99 \\
Severe adverse events SAEs n & 46 & 45 & 0.82 \\
Bronchoplumonary dysplasia n (\%) & $21(10.8)$ & $24(13.5)$ & 0.53 \\
Retinopathy of prematurity n (\%) & $12(6.4)$ & $14(8.3)$ & 0.64 \\
Intraventricular haemorrhage n (\%) & $38(18.4)$ & $28(14.8)$ & 0.41 \\
Haemangioma n infants (\%) & $35(17.0)$ & $34(18.0)$ & 0.89 \\
Haematocrit day 7-10, mean (SD) & $47.3(7.9)$ & $44.8(7.1)$ & 0.002 \\
\hline
\end{tabular}

Conclusions No significant adverse effects of early high-dose rhEpo treatment in very preterm infants were identified. The neuroprotective effect will be evaluated in 24 months.

\section{ASSOCIATION BETWEEN SECRETORY PHOSPHOLIPASE A2 SUBTYPE $V$ (PLA2G5) GENOTYPE AND ACUTE RESPIRATORY DISTRESS SYNDROME IN INFANTS}

doi:10.1136/archdischild-2012-302724.0057

D De Luca, A Minucci, L Gentile, M Piastra, M Antonelli, G Conti, ED Capoluongo. PICU and Lab of Clinical Molecular Biology, University Hospital A. Gemelli, Catholic University of the Sacred Heart, Roma, Italy

Background Secretory Phospholipase A2 (PLA2) has been linked with acute respiratory distress syndrome (ARDS) and its clinical severity and mortality. The enzyme subtype -V (PLA2G5) is expressed in the lung tissue. We aimed at sequencing its gene (HGNC:9038) in infants with ARDS. This study is a part of a multicentre project whose protocol has been published elsewhere.[1]

Methods 24 ARDS and 24 age-matched babies with no lung disease were enrolled. 50 healthy adult volunteers, who never had neither ARDS nor chronic pulmonary diseases, served as another control group. Genomic DNA was extracted from leukocytes, amplified by PCR and sequenced, analyzing the coding regions by SeqScape. Basic clinical data were recorded.

Results A polymorphism (p.G3G=c.9C>T) was detected in the gene PLA2G5 (exon 1). This variation was present in heterozygosis in $42 \%$ of controls and in $17 \%$ of patients, while homozygosis was detected in $21 \%$ of patients and in no controls $(p=0.022)$. Heterozygosis and homozygosis were present in $54 \%$ and $10 \%$ of adult controls, respectively. Homozygosis for such polymorphism led to an increased risk of ARDS (OR: 6.7; 95\% C.I.: [1.3-34.2]). Patients carrying this polymorphism had lower $\mathrm{PaO}_{2} / \mathrm{FiO}_{2}$ ratio $(104 \pm 29$ vs $147 \pm 53 ; p=0.039)$ and higher lung injury score at the diagnosis (3.7 $\pm 0.2 v s 3.2 \pm 0.4 ; p=0.031$ ).

Discussion These are the first findings about genetic association between PLA2 and ARDS. Variation in the PLA2G5 gene might be associated to an increased risk for ARDS as it may represent a marker of variations in other genes nearby PLA2G5, that may be involved in inflammation pathway.

[1] De Luca D, Capoluongo E, Rigo V \& Study group on Secretory Phospholipase in Paediatrics. BMC Pediatr 2011; 11:101.

\section{EFFECT OF VARESPLADIB-PROTECTED SURFACTANT IN CULTURED RAT ALVEOLAR MACROPHAGES STIMULATED WITH LPS}

doi:10.1136/archdischild-2012-302724.0058

'D De Luca, 'F Vendittelli, ${ }^{2} \mathrm{H}$ Fraser, 'L Gentile, ${ }^{2} \mathrm{~J}$ Trias, 'A Minucci, 'ED Capoluongo. ${ }^{1}$ PICU and Lab of Clinical Molecular Biology, Catholic University of the Sacred Heart, Rome, Italy; ${ }^{2}$ ANthera Pharmaceuticals, R\&D, Hayward, CA, USA

Background Secretory phospholipase A2 (sPLA2) is a crucial enzyme for inflammatory response and surfactant catabolism. Acute lung injury (ALI) is a life-threating syndrome characterized by surfactant dysfunction and raised levels of sPLA2. Varespladib is a potent selective sPLA2 inhibitor that is effective in animal models of ALI. Nothing is known about the joint administration surfactant+varespladib and we aimed at studying the effect on the sPLA2 pathway.

Methods $1 \times 10^{6}$ normal alveolar macrophages (from Rattus Norvegicus) were cultured in Ham'sF12 medium $+2 \%$ fetal bovine serum Cultures were incubated with $15 \mathrm{ng} / \mathrm{mL}$ LPS for $24 \mathrm{~h}$, then treated with $200 \mu$ g poractant- $\alpha, 90 \mu \mathrm{M}$ varespladib, both or nothing. These concentrations were those achieving $50 \%$ sPLA2 activity reduction in previous experiments. After $24 \mathrm{~h}$, culture supernatants were assayed for sPLA2 activity, free fatty acids (FFA) and total proteins concentrations.

Results sPLA2 activity corrected for the protein level is $0.26 \pm 0.02$, $0.24 \pm 0.02,0.24 \pm 0.02$ and $0.28 \pm 0.02 \mathrm{IU} / \mu \mathrm{g}$ in cultures treated with 